\title{
Registro de un nuevo helecho para la Flora de Honduras
}

Ruth Karina Hernández Cibrian*

Cyril Hardy Nelson Sutherland*

\section{RESUMEN}

Se describe el hallazgo del helecho Polypodium ursipes como planta nueva para la flora pteridófita de Honduras.

Palabras clave: Helechos, flora, Honduras

\section{ABSTRACT}

The finding of a new fern of Honduras is reported.

Key Words: Fern, flora, Honduras

*Ruth Karina Hernández Cibrian, sphagnum1@yahoo.com

*Cyril Hardy Nelson Sutherland, chnelsons@yahoo.com

Escuela de Biología, Universidad Nacional Autónoma de Honduras 


\section{INTRODUCCIÓN}

Aunque no se ha registrado totalmente la flora vascular de Honduras, se estima que puede representar aproximadamente el $2.5 \%$ de las 300,000 especies de plantas vasculares reportadas a nivel mundial. (Secretaria de Recursos Naturales y Ambiente, SERNA, 2001).Dentro de esta flora vascular se encuentran los helechos, que son plantas con un gran número de especies, adaptadas a diferentes hábitats y se encuentran con mayor abundancia en las regiones húmedas y templadas. Los helechos a pesar de tener una gran diversidad de formas y tamaños, no han sido objeto de mucho estudio. En Honduras destacan las siguientes publicaciones acerca de los helechos: Cruz, G. y M. Erazo (1977), Nelson, C., R. Gamarra y J. Fernández.(1996), Chang, P. 2002 y Ruth Hernández (2004).

\section{MATERIALES Y METODOS}

La investigación se realizó en la zona núcleo del parque nacional La Tigra (PNLT), específicamente en el sendero La Esperanza, ubicado entre 1,940 y 2,120 msnm, con una longitud de $2.5 \mathrm{~km}$ y la vegetación predominante es latifoliada muy diversa. El trabajo de campo se realizó durante los meses de septiembre a diciembre del año 2002 (estación lluviosa) y durante los meses de febrero y marzo del año 2003 (estación seca). Se establecieron y delimitaron 12 parcelas (no permanentes) 20x20 $\mathrm{m}$, ubicadas aleatoriamente a lo largo del sendero. Cada parcela fue dividida en 4 subparcelas de $10 \times 10 \mathrm{~m}$ para tener un total de 48 subparcelas. Alas parcelas $20 \times 20$ $\mathrm{m}$, se les asignó un número del 1 al 12 y las subparcelas se identificaron con las letras del abecedario a, b, c y d. Para la colecta de helechos se utilizó prensas de madera, tijeras de podar, cartones, papel periódico, alcohol al $70 \%$, bote atomizador, horno para secar plantas, GPS Magellan 315 y una cámara Canonn AE-1.La identificación de las diferentes especies de helechos se realizó utilizando claves taxonómicas, comparando los especimenes con los que se encuentran depositados en el Herbario de la Universidad Nacional Autónoma de Honduras (TEFH) y con la ayuda del Dr. Cyril Hardy Nelson y el Dr. John T. Mickel del New York Botanical Garden. Los duplicados de algunos de los ejemplares se encuentran depositados en el New York Botanical Garden (NY), Herbario Nacional Colombiano (COL) y los ejemplares de referencia se encuentran depositados en el Herbario Universidad Nacional Autónoma de Honduras (TEFH).

${ }^{8}$ Mencionan en su trabajo realizado en el parque nacional La Tigra un listado de 32 especies de helechos sin embargo, durante mi trabajo de investigación obtuve 38 nuevos registros dentro de los cuales sobresale Polypodium ursipes..

${ }^{9} \mathrm{~A}$ pesar de que es una guía ilustrada tiene solamente algunas fotografía de helechos. 


\section{DISCUSIÓN}

Polypodium Ursipes se encontró en el sendero La Esperanza a una altura de 2,020 msnm, el 27 de octubre del 2002, colectado por Ruth Karina Hernández Cibrián con número de colecta 227. El espécimen fue identificado por el Dr. John Thomas Mickel Pteridológo del New York Botanical Garden (NY). Se encuentran duplicados en el Herbario de La Universidad Nacional Autónoma de Honduras (TEFH) y Herbario New York Botanical Garden (NY). Polypodium ursipes forma parte del gran número de especies raras representada generalmente por un solo individuo lo cual puede deberse a que su capacidad de dispersión y reproducción no es muy elevada, además de que las poblaciones de especies que tienen pocos individuos no obtienen la cantidad de recursos (nutrientes) suficientes como las poblaciones que son abundantes y por consecuencia, esto conduce a su rareza. También puede decirse que su rareza puede ser el resultado de no haber muestreado el dosel superior.

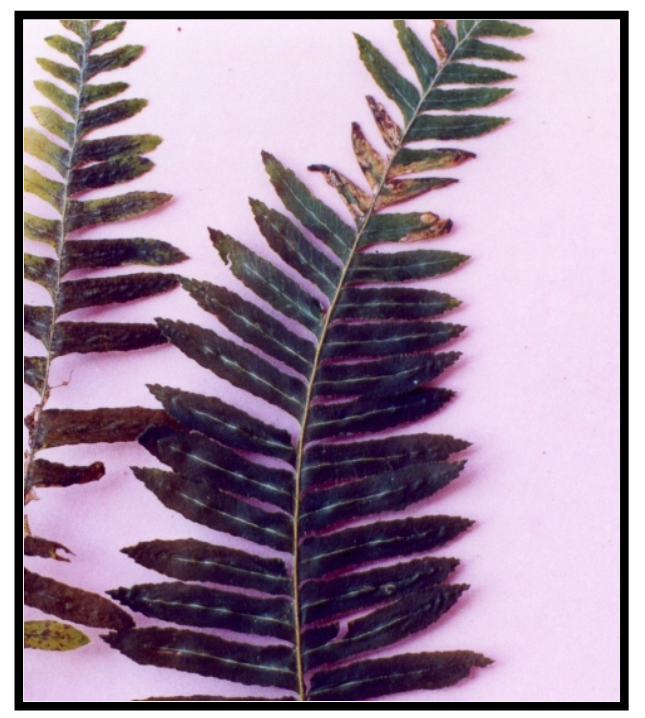

Polypodium ursipes

\section{CONCLUSIONES}

Con el hallazgo de Polypodium ursipes se enriquece la flora de Honduras. Deben realizarse investigaciones orientadas a conocer la diversidad de helechos, 
utilizando técnicas de muestreo en donde se analicen parámetros medioambientales además es importante conocer que uso le da la población hondureña a las diferentes especies de helechos y así generar información sobre este grupo de plantas.

\section{AGRADECIMIENTOS}

La realización de este artículo ha sido posible al trabajo de tesis realizado en el 2004 en el parque nacional La Tigra y al apoyo del Dr. y Cyril Nelson.

\section{BIBLIOGRAFÍA}

Chang, P. 2002. Guía ilustrada para la identificación de 31 especies de helechos encontrados en la reserva de la montaña Uyuca. El Zamorano. Escuela Agrícola Panamericana (EAP). Tesis. 1-42 p.

Cruz, G. y M, Erazo 1997. Análisis de la vegetación del bosque nebuloso "La Tigra" (reserva forestal San Juancito). Ceiba 21(2): 19-66.

Hernández, R. 2004. Diversidad de helechos del sendero La Esperanza del parque nacional La Tigra. Tesis 1-299 p. (de que institución)

Nelson, C., R. Gamarra y J. Fernández. (1996). Hondurensis plantarum vascularium catalagus. Pterydophyta. Fontqueria. 43: 1-223.

Honduras. Secretaria de Recursos Naturales (SERNA). 2001. Estudio sobre la biodiversidad biológica de la República de Honduras. Tegucigalpa: Multiprint; $p$. $1-158$. 